\title{
Arte-ciência-tecnologia e sistemas da arte na era da cultura digital: contexto Brasil
}

Art-science-technology and systems of art in the age of digital culture: context Brazil

Débora Aita Gasparetto 


\section{Resumo}

Este artigo propõe abordar a temática da arte-ciência-tecnologia na era da cultura digital a partir das suas relações com o sistema da arte vigente. Para isto nos baseamos em entrevistas disponibilizadas na publicação Arte-ciência-tecnologia: o sistema da arte em perspectiva (2014), a qual aponta caminhos para a pesquisa de doutorado da autora. Nesta oportunidade analisamos o contexto brasileiro em termos de produção-distribuição-consumo-preservação, a fim de constatar a inserção ou não da produção, também denominada arte digital, no sistema da arte contemporânea. A partir desta análise propomos uma reflexão sobre os sistemas da arte na contemporaneidade e a possibilidade de existência de um sistema particular para a arte-ciênciatecnologia em diálogo com o sistema da arte contemporânea, mas, sobretudo, com a cultura do início do século XX.

Palavras-chave: Arte-ciência-tecnologia; Arte digital; Cultura digital; Sistema da arte.

\section{Abstract}

This paper proposes to approach the theme of art-science-technology in the age of digital culture from their relationships with the current system of art. For it, we relied upon interviews made available in the publication Art-science-technology: the art system in perspective (2014), which points out ways for the author's doctoral research. In this opportunity, we analyze the Brazilian context in terms of production-distribution-consumption-preservation, in order to verify the insertion or not of the production, also nominated as digital art in the contemporary art system. From this analysis, we propose a reflection about the systems of art in contemporaneity and the possibility of existence of a particular system for art-science-technology in dialogue with the contemporary art system, but especially with the culture of the early twenty-first century.

Keywords: Art-science-technology; Digital art; Digital culture. Art system.

ISSN: 2175-2346 


\section{Introdução}

Temos nos debruçado sobre a produção em arte digital, termo utilizado como uma estratégia de inserção política na busca por fomentos a um campo específico, contudo seu conceito abrange obras na interface da arte-ciência-tecnologia. Esta produção acontece como sistema complexo, em que obra, dispositivos tecnológicos, espaço expositivo e público interagem entre si. Nosso foco de pesquisa sobre arte digital é reconhecer suas relações com o sistema da arte vigente, especialmente com o mainstream do sistema da arte contemporânea, para pensar na hipótese de existência de um sistema específico para esta produção no Brasil. Hipótese esta que estabelece relações com o "mundo da New Media Art", algo que é percebido por pesquisadores como Edward Shanken (2011) e Domenico Quaranta (2010), em um contexto internacional.

Para realizar as observações que propomos a seguir, este artigo se pauta em uma organização de entrevistas disponível no e-book Arte-ciência-tecnologia: o sistema da arte em perspectiva (2014), espaço em que mais de trinta artistas, curadores, historiadores da arte e pesquisadores especializados no assunto, nacionais e alguns internacionais, expõem suas opiniões sobre a inserção da arte digital no sistema da arte contemporânea, sobre as questões que a arte digital oferece ao sistema da arte, bem como os pilares de produção-distribuição-consumo-preservação. A partir dessas entrevistas buscamos analisar quais são as estruturas para atender as demandas da arte digital no Brasil.

É preciso lembrar que a arte digital, embora já tenha um histórico de produção consolidada, especialmente a partir dos anos 1990, pouco circula pelo sistema mainstream da arte contemporânea, menos ainda pelo mercado da arte, que é o grande responsável pelas articulações neste sistema mainstream. A crítica é praticamente inexistente nos meios tradicionais, assim como a preservação dessas obras/ projetos/trabalhos nas tradicionais instituições da arte.

No entanto, existe um circuito expositivo efervescente no Brasil, algo que se manteve dinâmico dos anos 2000 até 2012, quando uma série de redirecionamentos por parte da iniciativa público-privada encerrou projetos promissores. Mesmo assim, é possível verificar a existência de "faíscas" deste curto-circuito por vários estados do país, fruto de projetos relacionados às universidades ou à iniciativa de entusiastas. Isto se pode observar em um mapeamento realizado pelo projeto "O 'curto-circuito' da arte digital no Brasil" (2014).

Roberta Bosco (In: GASPARETTO, 2014) demonstra que a arte digital é a única produção genuína deste tempo, porque ela só foi possível a partir das tecnologias digitais, a partir da cultura digital na qual estamos imersos, que transforma em ritmo acelerado as relações humanas, comunicacionais, sociais, afetando todos os setores. Mas, por que esta produção tão contemporânea ainda não entrou definitivamente no sistema mainstream da arte contemporânea? Por que as maiores plataformas expositivas de arte contemporânea no Brasil, a exemplo da Bienal de São Paulo e da Bienal do Mercosul, pouco expõem arte digital? Situação que só piorou desde o final dos anos 1990 e início dos anos 2000, momento em que a produção parecia ocupar um lugar de destaque nas bienais brasileiras. Quais seriam os motivos para algumas raras galerias tentarem comercializá -la? Qual é o motivo de a arte digital não estar presente nas coleções de museus de arte contemporânea brasileiros, se é uma produção que inicia nos anos 1960 com Waldemar 
Cordeiro, mas se fortalece nos anos 1990 na potencialidade das redes? Quais podem ser as consequências dos redirecionamentos no setor das empresas privadas que eram as maiores investidoras da arte digital no país? Será que é possível criar uma solução de inserção e diálogo não apenas na teoria, mas também na prática?

Entre os motivos para esta pouca inserção, muitos entrevistados (In: GASPARETTO, 2014) citam certo preconceito e a falta de conhecimento da produção em arte digital por parte dos tradicionais agentes da arte contemporânea. Há um fosso conceitual entre os agentes do mainstream e a produção em arte digital. Ainda podemos citar como causas deste distanciamento: a falta de projetos educacionais de inserção, a dificuldade técnica/tecnológica de montagem das exposições e a dificuldade de mercado, pela "efemeridade" e "imaterialidade" das obras, o que tem sido superado internacionalmente com feiras específicas. Outro motivo que inviabiliza esta inserção no mercado, em relação ao Brasil, é o fato de a maioria dos artistas brasileiros que produzem arte digital estarem vinculados à academia, o que não ocasiona uma dedicação exclusiva à produção voltada ao mercado, salvo raras exceções. Mas será que podemos pensar em um mercado em termos tradicionais para este tipo de arte? Como as redes telemáticas interferem nos processos de produção/distribuição/consumo da arte digital? Como se pode pensar em um sistema específico em um momento no qual se fala em hibridações, cruzamentos, borramentos de limites e fronteiras? E quais seriam as estruturas deste sistema no caso da arte digital no Brasil? Este artigo talvez coloque mais dúvidas do que respostas fechadas, contribuindo para repensar a arte e seu sistema na atualidade em diálogo com a cultura digital na qual está imerso.

\section{Alguns apontamentos sobre o estado atual da cultura digital}

O livro Cultura digital.br (2009) concebe o pensamento de alguns brasileiros sobre a cultura digital. Realizada no âmbito do Ministério da Cultura brasileiro, a publicação traz algumas opiniões de agentes de áreas diversas, que demonstram as transformações ocasionadas pelo digital na cultura e também o papel de destaque que a arte assume, sendo observada de perto pela ciência.

O economista Ladislau Dowbor apresenta algumas opiniões interessantes para pensar a arte e o sistema hoje, pois podemos relacioná-la ao que acontece com a cultura digital. Dowbor percebe o papel do produtor também como agente da cultura, sem precisar necessariamente de intermediários e uma mudança em um nível econômico proporcionada por esta nova cultura:

Hoje estamos nos deslocando para uma economia onde a produção física tem muito menos importância no processo de valoração [...] Quando o conhecimento se torna o principal elemento de valor de um produto determinado, as relações mudam. (DOWBOR In: SAVAZONI; COHN, 2009, pp. 56-57)

Esta nova economia é descentralizada porque a noção de espaço e território também foi alterada, qualquer artista, em qualquer parte do mundo com acesso à internet pode se conectar e disponibilizar seus trabalhos. E o público, nas mesmas condições, pode experienciar estes trabalhos. 
Em 2011, Mariana Fossatti e Jorge Gemetto organizam a publicação "Arte joven y cultura digital", a partir de um curso realizado no Centro Cultural Ártica, contanto com a opinião de mais de 400 pessoas Ibero-americanas. Essa publicação também nos ajuda a pensar nas relações de produção, distribuição e consumo da arte em meio à cultura digital, uma cultura que traz um potencial de democratização dos meios de produção, oportuniza o acesso e o intercâmbio (FOSSATTI; GEMETTO, 2011). Entre as mudanças percebidas na pesquisa eles apontam o fato de que os dispositivos tecnológicos e as redes extrapolam os limites institucionais, dando voz aos artistas independentes, às plurais manifestações culturais autônomas e à criatividade social. Evidentemente a pesquisa não é ingênua, demonstrando que nem tudo é tão livre e democrático assim, mas talvez essa seja a primeira vez na história que este potencial de coletividade é alcançado.

Não é apenas ao artista que a cultura digital se abre, mas à sociedade como um todo, trazendo figuras como a do "prosumidor", que relaciona o produtor ao consumidor. Entre as palavras que podem definir a cultura digital destacamos a conectividade, a produção aberta à participação, o intercâmbio, a inteligência coletiva. Os produtores e consumidores estão tão próximos que os tradicionais intermediários já não têm um papel tão decisivo ou ativo e a noção de mercado na cultura digital também se transforma, como percebemos também nas entrevistas (In: Savazoni; Cohn, 2009). Não podemos negar o papel dos tradicionais mercados, economias e agentes que regem o sistema no qual este processo se articula, mas sem dúvida a cultura digital desafia estas noções tradicionais, oferecendo ao artista novos modos de inserção e até mesmo de financiamento de seus projetos, por "crowdfunding", por exemplo, um tipo de financiamento coletivo.

"Arte joven y cultura digital" (2011) demonstra que a gestão cultural independente tem um promissor desenvolvimento, oportunizando aos artistas e público um encontro condizente com este momento cultural que vivemos, independentemente de ser digital ou analógica a arte que é produzida. Essas redes e tecnologias digitais também têm sido ferramentas para unir as pessoas em manifestações de grupos, minorias, causas ou nações que jamais tiveram esse potencial de articulação que as redes oferecem. Rebeliões e descontentamentos que ajudam a repensar a vida em sociedade, o sistema capitalista e o papel da cultura digital.

Outro aspecto deste estado da cultura atual é a convergência. Henri Jenkins (2009) dedica-se a compreender o que entende como a "cultura da convergência", dimensionada pelos meios de comunicação, pela cultura participativa e inteligência coletiva. Para este autor, a convergência é uma transformação cultural na qual os "[...] consumidores são incentivados a procurar novas informações e fazer conexões em meio a conteúdos de mídia dispersos" (JENKINS, 2009, pp.29-30). Ele vai pensar na interação das mídias e não na sua dissolução em um único aparelho, assim essas mídias interagem de modos complexos. Esta relação apontada por Jenkins pode ser uma boa analogia para o sistema da arte, pois o sistema da arte contemporânea não precisa englobar o "circuito" já estabelecido da arte digital, mas interagir com ele, criando novas conexões ao campo da arte e da cultura digital, algo que flui por vários canais.

Entretanto, não podemos nos esquecer das grandes corporações que monopolizam conteúdos culturais, direitos autorais e mercados, e que seus papéis vêm sendo amplamente discutidos, assim como os papéis das poderosas instituições artísticas que também 
expandem sua atuação para as redes informacionais. Nos últimos anos, percebemos também a perversa dominação de dados por nações poderosas que demonstram que informação é poder, como os Estados Unidos no escândalo envolvendo inclusive investigações no governo brasileiro e a exposição de dados via empresas como Google, Apple e Facebook, escândalo detonado por Edward Snowden. E ainda as redes sociais como o Facebook têm demonstrado muito bem como fazer os seus usuários de cobaias e, legalmente, em estudos de comportamento voltado ao marketing da própria rede. Ou ainda os "mega" vazamentos e exposição de dados, crescentes em 2013, nos fazem repensar cada vez mais as redes informacionais e a cultura digital na qual estamos imersos. E se aparentemente há uma linearidade em termos de estrutura, na prática os jogos de poder e interesse ainda dão as cartas no mundo dos negócios, da política e também das artes.

Reconhecendo este contexto, ainda que de modo breve, podemos observar no campo da arte, em especial da arte digital, a influência da cultura digital. Esta traz um modelo mais linear e horizontal de produção-distribuição-consumo, não descartando jogos de interesse ou poder, mas equilibrando ambos. Esta é uma produção que questiona e repensa constantemente arte, cultura e sociedade de seu tempo, e isso não acontece como reflexo da sociedade contemporânea, mas como parte ativa que ajuda a construí-la.

Para tratar do contexto brasileiro, podemos pensar em um sistema em que o consumo nem sempre tem um valor financeiro envolvido, mas é realizado pela própria experiência do usuário na condição de "prosumidor" das obras/projetos/trabalhos. O público tem um papel primordial na obra e, conforme lembra Fernando Fogliano (In: GASPARETTO, 2014), o corpo do público é chamado a integrar a obra. O papel do artista é proporcionar ao público a experiência, que é diferente para cada interator.

\section{A produção em arte digital no Brasil}

Os artistas brasileiros não possuem uma produção unificada, ao contrário, cada grupo de artistas e cada região do país tem as suas especificidades. Entre algumas características que abrangem muitos grupos está o trabalho com baixa tecnologia e em determinados casos a subversão dos dispositivos tecnológicos. Talvez isso aconteça em função de que o Brasil não é um produtor de tecnologia, mas um usuário, como lembram alguns entrevistados (In: GASPARETTO, 2014).

Outra característica da produção em arte digital, não somente do Brasil mas também de outros países, é o vínculo destes artistas com as universidades e ainda o incentivo da iniciativa privada, no caso brasileiro, por meio de bolsas e prêmios, além dos editais de fomento cultural oferecidos pelas leis de incentivo à cultura, via redução de impostos, e de bolsas oferecidas pelos editais públicos. Embora estes não sejam específicos à arte digital, contribuem para tirar alguns projetos produtivos e expositivos do papel e são os entusiastas, artistas, curadores e profissionais da área os responsáveis por viabilizar estas articulações.

Mesmo diferenciada, não apenas pela variedade de dispositivos tecnológicos usados para fazer arte, mas pelas questões específicas trabalhadas pelos artistas e grupos, é possível apresentar um panorama geral da história da produção em arte digital no Brasil e pensar o seu momento atual, para na sequência discutir a relação desta produção com o sistema 
da arte. Para isto é importante pensar que onde há produção também há exposição, o que pode nos ajudar a caracterizar este sistema da arte digital brasileiro.

Milton Sogabe (2009) aponta três gerações da arte e tecnologia no país, em que a primeira, cujas manifestações ainda são isoladas, inicia com Abraham Palatnik e Waldemar Cordeiro, nos anos 1960. A segunda geração é constituída por grupos de artistas vinculados ao contexto acadêmico dos anos 1980; entre os nomes desta geração Julio Plaza ocupa um lugar de destaque ao lado do IPAT (Instituto de Pesquisa em Arte e Tecnologia), o qual forma pesquisadores que passam a atuar em diversos lugares do país. Ao mesmo tempo, Sogabe (In: GASPARETTO, 2014) demonstra que a segunda geração se origina nas universidades e em torno do campo da arte, esta geração formou outras gerações, a partir de orientações em programas de Pós-Graduação. Já a terceira geração não está necessariamente vinculada às universidades, nem mesmo ao campo da arte, são artistas ou grupos que nasceram e cresceram no contexto das redes e da cultura digital. Ele argumenta que diferentemente da primeira e segunda geração, esta terceira tem a facilidade de acesso à tecnologia, não precisando necessariamente atuar em equipados laboratórios para produzir.

Arlindo Machado (2005) evidencia que a produção em arte e tecnologia no Brasil tem algumas características relacionadas ao contexto social no qual se desenvolve inicialmente. Ele lembra que, ainda nos tempos de ditadura militar, artistas como Waldemar Cordeiro surgem como personagens críticos, com obras de natureza política e social, em meio ao regime militar. $O$ autor também explica que a produção brasileira foi bastante precoce em comparação com outros países da América Latina, devido ao aumento do acesso aos computadores. E com um tom de envolvimento pessoal no curso da história da arte e tecnologia no país, lembra, referindo-se aos anos 1970-1980:

Nessa época, quando ainda éramos um grupo bastante reduzido de pessoas, quando a tecnologia e a ciência ainda eram consideradas intromissões mais ou menos estranhas e até certo ponto indesejáveis no universo estabelecido das artes oficiais, sentíamos que era preciso juntar forças para implantar no Brasil, tal como já vinha acontecendo em outros lugares do mundo, um novo campo de intervenção estética, e também para dar legitimidade a uma prática artística que era vista então com uma certa desconfiança pela ala hegemônica da cultura. (MACHADO, 2005, p. 77)

Machado acredita que ao longo do tempo essas práticas "(...) foram perdendo seu caráter marginal e quase underground, para rapidamente se converterem nas novas formas hegemônicas da produção artística" (MACHADO, 2005, p. 78). O autor também observa a efervescência de festivais e mostras, mas parece decepcionado com a "banalização de rotinas já cristalizadas na história da arte" e práticas que assumem um discurso em consonância com os valores dominantes da arte. Sua opinião está em sintonia com muitas críticas tecidas em discussões pelos principais eventos da arte digital no país, em relação a obras que parecem mais demonstrações da tecnologia do que arte, à diminuição da poética frente aos experimentalismos tecnológicos, os discursos técnicos roubando o espaço da arte criativa e crítica.

O autor, no entanto, também reconhece que os critérios e críticas também não estão suficientemente maduros para "julgar" tais obras. Ele sugere um restabeleci- 
mento destas práticas com “(...) a melhor tradição de inconformismo da arte contemporânea" (MACHADO, 2005, p. 78). E ainda nos convida a buscar critérios mais rigorosos para julgar esta produção, separando o "joio do trigo".

Contudo, será que não é característica desta produção também o que ele chama de "joio", os experimentalismos tecnológicos e as obras com caráter de entretenimento? É evidente que a poética deve se sobressair, mas não há como pensar este momento sem levar em conta esta outra produção, mais fixada nas descobertas sobre o potencial das tecnologias, ou pensar o que tais experimentalismos podem trazer de tensionamentos para o mundo da arte.

Em relação ao contexto histórico da arte digital, a partir destes autores, entende-se que a primeira geração a fazer o uso do computador na arte, como ferramenta, nasce com Waldemar Cordeiro e assume um caráter político de contestação à ditadura militar. Assim como Cordeiro, outros artistas daquele período, do final dos anos 1960 ao início dos anos 1980, também utilizavam os meios de comunicação disponíveis na época para fazer arte de cunho social e político. Entre eles, artistas como Paulo Bruscky, além de outros que, mesmo sem utilizar os meios de comunicação ou computadores, também questionavam o regime vigente e transitavam à margem do sistema das artes, como Cildo Meireles, o qual atualmente já foi incorporado ao sistema das artes. E, a partir dos anos 1990, com as possibilidades que as redes telemáticas abriram, muitos artistas que já trabalhavam com arte postal e fax arte, a exemplo de Gilbertto Prado, também passaram a investigar as possibilidades do ciberespaço destas redes. Nos anos 2000, com a profusão de festivais de arte digital pelo país, e com o acesso cada vez mais facilitado às tecnologias, a terceira geração vem assumindo diferentes faces.

Independentemente das gerações citadas, atualmente pode-se apontar proximidades de pesquisas inclusive entre artistas de diferentes gerações e regiões brasileiras. A partir da variedade de possibilidades aberta pelas tecnologias, percebe-se que existem os grupos de artistas da segunda geração, que trabalham com conceitos muito próximos daqueles do mundo da arte contemporânea, pensando acima de tudo a arte. Entre estes destacamos, por exemplo, em São Paulo, a poética da invisibilidade traçada por Gilbertto Prado e o Grupo Poéticas Digitais, os experimentos pautados na ciência e na natureza da equipe interdisciplinar SCIArts, ou as obras da artista Anna Barros, que usa alta tecnologia para falar de tempo e memória em suas experiências com nanoarte. Afinal, como lembra Agnus Valente, artista que também pactua com esta geração, "Arte é Arte" (VALENTE In: GASPARETTO, 2014). Estes artistas atuam nas universidades e conseguem manter seus trabalhos articulados a grupos de pesquisa. Mesmo o SCIArts, que é um grupo sem vínculo acadêmico, tem todos os seus integrantes vinculados à universidade.

Às poéticas do segundo grupo apontado por Sogabe (2009) somam-se os trabalhos do Grupo Nano, do Rio de Janeiro, liderado por Malu Fragoso e Guto Nóbrega, produzindo a partir das redes telemáticas, dos organismos híbridos, da robótica e pensando a relação entre homem, máquinas e outros modos de existência. Estas experiências parecem ser um vínculo entre a segunda geração que está interessada em produzir arte, mas ao mesmo tempo, a partir da entrevista de Guto Nóbrega (In: GASPARETTO, 2014), percebemos que ele repensa o próprio conceito de arte, inserindo a questão do humano e dos objetos técnicos, algo extremamente pertinente para repensar o próprio sistema da arte. 
Em Minas Gerais observamos vertentes distintas de artistas da terceira geração, uma é a da gambiarra, que de certo modo assume diferentes faces pelo país, tendo como foco o experimentalismo e o contexto digital da terceira geração a que Milton Sogabe (2009) se refere, demonstrando ser possível produzir arte digital com baixa tecnologia. Outra vertente muito forte em Minas Gerais está vinculada à arte generativa, às produções que envolvem maior complexidade e até mesmo alta tecnologia. Uma vertente não exclui a outra, as duas dialogam muito bem por sinal. A primeira vertente pode ser exemplificada com os trabalhos do Gambiologia e a segunda com os de Henrique Roscoe, conhecido como Impar. Assim como as primeiras gerações, o foco destes trabalhos é o campo da arte, embora muitos destes pesquisadores não sejam artistas de formação acadêmica; Henrique, por exemplo, é formado em Engenharia Eletrônica e Comunicação Social, mas assume em seus trabalhos a transdisciplinaridade de uma equipe. Em Minas Gerais também observamos o cruzamento bastante forte com o campo da música, algo que se percebe no trabalho de Henrique Roscoe, por exemplo.

A mobilidade é característica de uma terceira vertente explorada neste Estado, algo justificável com o fomento que a região recebeu à produção por parte da empresa de telefonia Vivo, com o Vivo Arte.Mov. Fomento este que cessou em 2012. Mesmo que as obras/projetos/trabalhos não ilustrem isso, fica claro que esta também é uma questão discutida na região. A produção em mobile arte tem na figura de Lucas Bambozzi um dos maiores expoentes. Outra peculiaridade é que estes artistas e grupos mineiros são, em sua maioria, autônomos à academia, como é o caso dos artistas e grupos aqui citados e do Marginalia+Lab, um espaço autônomo que encerrou suas atividades em 2013.

Outras regiões do país têm na mobilidade, na cartografia e natureza semelhanças entre grupos de pesquisadores como, por exemplo, em Belém do Pará, com artistas como Val Sampaio; na Bahia, com Karla Brunet e o grupo Ecoarte; ou em Florianópolis, com Yara Guasque. Estas pesquisadoras estão vinculadas ao contexto das universidades e apresentam preocupações ativistas em suas pesquisas, encaminhando suas discussões ao contexto mais político e social, algo ainda mais forte no trabalho de Yara Guasque.

Também com este cunho mais ativista, a artista que faz parte da segunda geração, Suzete Venturelli, em parceria com o grupo MidiaLab UNB, aborda questões políticas que lembram de certo modo a primeira geração, especialmente a figura de Waldemar Codeiro, no entanto trabalhando o computador enquanto sistema complexo. Em obras como Brasília Invaders (2013) ou Paulista Invaders (2013), por exemplo, é perceptível esta inquietação política e social, mas ao mesmo tempo, imersa na dinâmica da cultura digital, do experimentalismo e de trabalhos em gamearte e entretenimento, que, a nosso ver, também é crítico-sensível. Simultaneamente ao trabalho do grupo atuando no contexto acadêmico, observa-se sua articulação nas iniciativas independentes. Nesta linha mais ativista, o artista Fábio Fon e sua companheira Soraya Braz, em São Paulo, já são da terceira geração, mas não se desvinculam do mundo da arte, mesmo trabalhando com as tecnologias. Ambos questionam inclusive as tecnologias, ou ao menos nos fazem pensar sobre elas e o seu uso, algo que também se observa no trabalho de Lucas Bambozzi, por exemplo.

Em relação às regiões brasileiras, observa-se que a região Sul, especialmente o Rio Grande do Sul, ainda está muito vinculada às "velhas tecnologias", como percebe 
Daniela Kern (2013). Isso não significa dizer que se trabalha com baixa tecnologia, mas principalmente com vídeo e fotografia, em uma perspectiva "retrô" e de obsolescência tecnológica e isso ocorre junto à geração atual de jovens artistas. Yara Guasque (In: GASPARETTO, 2014) também aponta que em Florianópolis, mesmo existindo um polo tecnológico, os artistas não se unem aos programadores, havendo ainda uma distância.

No Rio Grande do Sul, o que se percebe, no entanto, é a existência de uma forte pesquisa teórica, embora com pouca produção artística que posicione o estado no cenário nacional da arte digital. Mesmo que os gaúchos tenham como referência a figura de Diana Domingues, artista da segunda geração, extremamente atuante entre os anos 1990 e meados dos anos 2000, em obras/projetos/trabalhos entendidos como sistema e envolvendo alta tecnologia, com o encerramento do Grupo Artecno e a saída de Diana da UCS, muito se perdeu para o campo da arte-ciência-tecnologia gaúcho. As principais contribuições no sentido de suprir esta carência vêm do Labart/UFSM, que tem em Nara Cristina Santos um porto teórico para as experimentações artísticas a que o laboratório vem se abrindo na formação de jovens artistas. Recentemente o Labinter/ UFSM, coordenado por Andréia Oliveira Machado, também está se posicionando com produções em arte digital. Entre os jovens artistas gaúchos, alguns estão mais próximos da gamearte, em trabalhos como os de Anelise Witt e Marcos Chichelero, ou ainda das performances audiovisuais e interativas, como o trabalho de Fernando Codevilla.

Na UFRGS as pesquisas na linha de arte e tecnologia ficam por conta de Sandra Rey, voltada à fotografia e ao vídeo, Maria Amélia Bulhões, voltada à teoria em web arte e Alberto Semeler, artista atuante no circuito das universidades. Alberto Semeler desenvolve pesquisas em neuroarte, envolvendo neurociência e alta tecnologia.

Tania Fraga, que atua entre São Paulo e Brasília, também trabalha com neurociência e pesquisas com tecnologias de ponta. Ambos, Alberto e Tania, também estão interessados na experiência estética e, no caso de Alberto, fisiológica, o que pode proporcionar ao interator. Isto indica que não há uma unidade na produção em arte digital brasileira.

No Nordeste destaca-se o trabalho de Jarbas Jácome, que não tem formação em artes, sendo graduado em Ciência da Computação. Atualmente, Jarbas é professor na UFRB e suas oficinas envolvendo arte, tecnologia e música circulam pelos principais eventos de arte digital do país. Em Pernambuco, observamos que da área da informática saem os artistas que trabalham com arte digital, como Jarbas, formado pelo Cin -UFPE, muito vinculados à cultura digital. E na Bahia a produção em arte e tecnologia assume um vínculo muito forte com a dança, com o cinema e com a música.

Em Goiás também existe uma forte pesquisa em arte digital, por meio do MediaLab UFG, representado pela figura de Cleomar Rocha. Percebe-se que grande parte das pesquisas realizadas neste laboratório tem uma relação muito próxima com o design e vincula-se à terceira geração, imersa na cultura digital.

Há também artistas que se destacaram por meio de prêmios e incentivos. Esses, em maior parte, não estão vinculados à academia e conseguiram se inserir no mercado da arte contemporânea, inclusive sendo representados por galerias, como Eduardo Kac. Atualmente, o artista da segunda geração é um dos brasileiros mais reconhecidos no cenário internacional com suas experiências envolvendo bioarte. Raquel Kogan, embora tenha grande parte do seu currículo vinculado aos eventos de arte digital, consegue também circular 
por bienais e eventos de arte contemporânea. Entre alguns dos raros artistas brasileiros representados por galerias, destacamos Gisela Motta \& Leandro Lima, Fernando Velásquez, Kátia Maciel e Lucas Bambozzi. Ainda é preciso reconhecer alguns artistas como Rejane Cantoni e Daniela Kutschat, as quais têm obras que integram o acervo do ZKM (Centro de Arte e Mídia de Karlsruhe) e também do Itaú Cultural e conseguem uma inserção maior no sistema da arte contemporânea. Pode-se dizer que tais artistas atuam no "entre", transitam pelos dois "sistemas" e carregam características de ambos.

Entre as tendências recorrentes na produção atual, o mapping é um recurso que também tem sido bastante explorado entre os artistas brasileiros, talvez pela facilidade de aproximar quem já tem certa intimidade com o vídeo do universo interativo. Artistas que adotam este recurso normalmente se inserem em um circuito de exposição mais próximo do público e das ruas. Roberta Carvalho, artista de Belém/ PA, é um exemplo de como unir arte, tecnologia, natureza e questões de memória e identidade através de projeções mapeadas. Ela também é responsável pelo FAM (Festival Amazônia Mapping), festival que aconteceu em 2013 especificamente sobre esta temática, aproximando-se também do universo dos VJs.

E há ainda aqueles que talvez nem se consideram artistas, como mencionam alguns entrevistados (In: GASPARETTO, 2014). Entre estes alguns VJs, criativos do cinema e da música e pessoas vinculadas ao universo hacker, da comunicação, do design e informática, mas que produzem trabalhos que certamente circulariam, e alguns até circulam, no sistema da arte digital. Entre estes, os primeiros estão muito ligados ao universo da música e das performances, muitos trabalhando com Live Cinema. Já os outros estão muito mais vinculados à cultura digital, às questões ativistas, às discussões sobre softwares livres, programação e códigos. Como exemplo dos primeiros, podemos citar o VJ Spetto; dos voltados à cultura hacker, grupos como a Casa da Cultura Digital, em vários lugares do país; e, citado por Yara Guasque, o Tarrafa Hackerspace, de Florianópolis.

Maria Luiza Fragoso (In: GASPARETTO, 2014) cita que há menos de uma década, os jovens artistas acabaram reunindo-se em laboratórios de garagem e residências artísticas, na investigação compartilhada de hardware e software. Conforme ela, o movimento internacional DIY (faça você mesmo) é algo que está se disseminando pelo Brasil, ao tratar de questões ambientais, políticas e sociais, integrando comunidades e "[...] realizando uma inclusão digital no mundo das artes e da inovação, sem a necessidade de institucionalizar, ou promover políticas públicas." (FRAGOSO In: GASPARETTO, 2014). Percebemos que esta é uma vertente importante da produção em arte digital brasileira e aqui há uma significativa produção, no entanto raramente é reconhecida e absorvida pelo sistema mainstream da arte. Entre os projetos que seguem essa linha em termos de produção-exposição, podemos citar o Nuvem, um programa internacional de residências artísticas, o HiperOrgânicos, com os espaços de criação e o festival Tropixel.

Ainda observamos uma produção mais experimental, associada à tecnologia e ao desenvolvimento tecnológico, em projetos que nem sempre estão preocupados com a poética artística ou estética, mas que talvez estejam mais interessados no entretenimento. Muitos destes são acusados por isso, e o FILE é um dos festivais que não tem medo de expô-los, então também acaba sendo criticado, mas o FILE propõe mostrar linguagens eletrônicas, não necessariamente arte. No entanto é inegável que o FILE, 
assim como projetos mais relacionados ao desenvolvimento tecnológico ou à experimentação aproximam o público e muitas vezes são expostos justamente para atraí-lo.

Notamos na produção brasileira que os grupos vinculados às universidades apresentam forte referencial teórico e conceitual que acompanha as obras-projetos trabalhos, algo que é perceptível mais especificamente, mas não apenas, em artistas que mantêm um vínculo com a academia, nas diversas regiões do país. Observamos que há uma amadurecida pesquisa prático-teórica, por parte destes grupos, sem dúvida com grande chance de ultrapassar as barreiras ainda impostas pelo tradicional sistema mainstream da arte contemporânea. Tais artistas têm articulação internacional com outros centros e grupos de pesquisa. Conforme demonstra Agnus Valente (In: GASPARETTO, 2014) por meio de suas próprias estratégias de difusão, os artistas de hoje são os "agenciadores" da sua inserção e fortalecimento no circuito artístico. E diálogos já estão acontecendo, especialmente por parte de artistas e curadores com formação em arte e tecnologia, os quais percebem a arte independentemente dos dispositivos tecnológicos que a compõem. Ao mesmo tempo Yara Guasque traz uma contribuição muito importante para pensar o cenário da arte em meio à cultura digital: "Talvez a nossa produção e o viés que estamos procurando, acabe inviabilizando de vermos outros trabalhos como trabalhos artísticos" (GUASQUE In: GASPARETTO, 2014, p. 39). Olhar para além da arte é algo fundamental para um curador hoje.

Daniela Bousso, Yara Guasque, Niura Borges e Maria Amélia Bulhões (In: GASPARETTO, 2014) demonstram que, no entanto, um dos motivos para a pouca inserção no sistema das artes vigente é que os trabalhos realizados em âmbito acadêmico não chegam a ser consistentes no que concerne ao mercado e ao mainstream. Isto ocorre porque os artistas não conseguem dedicar-se integralmente a sua promoção e "pós-venda". Tais trabalhos ainda não têm o suporte financeiro que requer a sua exposição, divulgação e manutenção no sistema mainstream. Por mais que muitas destas obras sejam geniais, ainda apresentam problemas técnicos, algo que pode ser resolvido com mediadores treinados e um melhor acabamento nas obras, pensando sua manutenção e preservação.

Em relação aos espaços de distribuição da arte digital no Brasil, percebemos que eles acompanham os espaços de produção. Assim, estão vinculados às universidades, aos centros culturais financiados pela iniciativa privada, que na virada do século XXI também investia em laboratórios de produção, nas iniciativas independentes patrocinadas por leis de incentivo à cultura, ou nos espaços autônomos.

\section{Distribuição/Consumo da arte digital no Brasil}

Proliferam-se mostras de arte em interface com as variadas linguagens da tecnologia nos anos 1990, como apontam a Enciclopédia do Itaú Cultural, Priscila Arantes (2005) e Gilbertto Prado (2003). E no início dos anos 2000 é a vez dos festivais e eventos específicos de arte digital, como o FILE - Festival Internacional de Linguagem Eletrônica (2000 -, São Paulo e descentralizado), o Emoção Art.ficial - Bienal Internacional de Arte e Tecnologia do Itaú Cultural (2002-2012, São Paulo), o \#.ART - Encontro Internacional de Arte e Tecnologia, desde 1989, mas anualmente a partir de 2007, em Brasília, o On_Off (2005-, São Paulo), o Vivo Arte.Mov (2006-2012, Belo Horizonte e descentralizado), o Simpósio de Arte Contemporânea PPGART/UFSM, 
que em diversas edições esteve direcionado à arte e tecnologia (2006-, Santa Maria) e que em 2014 traz o FACTORS 1.0 - Festival de Arte Ciência e Tecnologia do RS, o FAD - Festival de Arte Digital (2007-, Belo Horizonte), a Mlc Mostra Live Cinema (2007-, Rio de Janeiro), o FAM - Festival Internacional de Arte e Mídia (2009-2010, Brasília), o Continuum - Festival de Arte e Tecnologia do Recife (2009-), o FAT - Festival de Arte e Tecnologia (2009-, Mato Grosso do Sul), a Mostra 3M de Arte Digital (2010-, São Paulo), o Hiperorgânicos - Simpósio Internacional e Laboratório Aberto de Pesquisa em Arte, Hibridação e Biotelemática (2010-, Rio de Janeiro), o Encontro Internacional de Grupos de Pesquisa: "Convergências entre Arte, Ciência, Tecnologia \& Realidades Mistas" - Latitudes-Atitudes (2010-, São Paulo), o Salão Xumucuís de Arte Digital (2011-, Belém), o 10 Dimensões: Diálogos em rede, corpo, arte e tecnologia (2011-, Natal), o SP_Urban Digital Festival (2012-, São Paulo), o SIIMI - Simpósio Internacional de Inovação em Mídias Interativas (2012-, Goiás), FAM - Festival Amazônia Mapping (2013-, Belém), Reconvexo - Festival Nacional de Vídeo-Projeções Mapeadas (2013-, Recôncavo Baiano), Tropixel - Arte, Ciência, Tecnologia e Sociedade (2013, Juiz de Fora e Ubatuba) e o \# FIART - Festival Internacional de Arte e Tecnologia (2014, Brasília). Para citar algumas "faíscas" do circuito expositivo da arte digital brasileira. Também é imprescindível citar a Galeria de Arte Digital do SESI-FIESP, a primeira galeria a céu aberto da América Latina, inaugurada em 2012, e desde então traz interessantes curadorias sob responsabilidade da Verve Cultural.

Consideramos que os próprios eventos têm sido repensados, por exemplo, o FAD, que atualmente, conforme os idealizadores, busca obras que exploram outros modos de expor a produção, não apenas telas e computadores, mas algo que valorize estas obras pela arte, não apenas pela tecnologia. Em Belém do Pará, o Salão Xumucuís de Arte Digital de 2014 foi além dos tradicionais espaços expositivos e ocupou a cidade. Estas iniciativas dialogam com a percepção de Guto Nóbrega de que muitos festivais, embora sejam específicos "[...] ainda se estruturam em modos de visibilidade e experiência artística conforme modelos de um paradigma anterior" (NÓBREGA In: GASPARETTO, 2014, p. 21). Então, já observamos em alguns festivais esta busca por modelos expositivos específicos e dinâmicos que acompanhem a produção.

Uma particularidade destes eventos é que a maioria deles não traz somente a exposição, mas discussões a respeito da produção, em simpósios, e o que é ainda mais relevante é que a maioria deles apresenta espaços de workshops e oficinas. Isto dialoga com o que há de mais incrível na cultura digital, o compartilhamento, a troca, e a possibilidade de agregar outros agentes criativos a este circuito. Esta formação de artistas também é observada em cursos específicos de programação, como Processing e Arduíno, algumas das ferramentas mais utilizadas pelos artistas digitais, entre muitos outros cursos, tanto em centros de formação, quanto em espaços originalmente destinados à cultura hacker, como os MídiaLabs, Ponto Labs e espaços de criação livres, como observa Yara Guasque (In: GASPARETTO, 2014).

Estes eventos demonstram que em diferentes regiões do país há um circuito de produção-exposição associado e independente dos tradicionais circuitos da arte contemporânea. Normalmente são os próprios artistas, curadores ou entusiastas que já têm um conhecimento teórico, ao menos, em arte digital, que articulam este circuito e tam- 
bém circulam entre os eventos citados. É nestes locais que acontece o consumo da produção em arte digital, em nível de experiência ao interator, não de consumo no sentido tradicional. Então podemos pensar em agentes distintos daqueles que circulam no sistema mainstream da arte contemporânea (museus, galerias, feiras de arte, bienais).

A arte digital tem na produção-distribuição-consumo uma estrutura de certo modo linear no Brasil, pois está associada a um modelo que dialoga com a cultura digital. Evidentemente, em um espaço de globalização, percebemos que instituições poderosas também no sistema da arte digital criam suas próprias regras e convenções, demarcando espaços e inserindo artistas em suas coleções e no mercado; internacionalmente podemos citar o ZKM e o Ars Electronica, no Brasil, até pouco tempo podíamos citar o Itaú Cultural.

\section{Preservação}

A preservação da arte digital é um grande motivo ou uma grande desculpa para que os tradicionais agentes da arte contemporânea pouco se aproximem da produção. Acusadas de efêmeras e/ou imateriais, estas obras têm sido deixadas de lado na história da arte que é contada pelos museus. Mesmo que alguns dos eventos citados aconteçam em espaços da arte contemporânea, estas obras, como percebeu Silvana Bonne (2013), não são adquiridas pelos acervos de tais instituições e grande parte da história da arte digital brasileira se perdeu em termos de preservação. Muitos dos entrevistados (In: GASPARETTO, 2014) também observam a conservação e manutenção destas obras como um problema. No entanto, discussões importantes que vinham sendo traçadas entre artistas, galeristas e instituições, o que pode ser conferido em Bousso (2002), acabaram se perdendo. É de extrema urgência que estas discussões sejam retomadas. Por isso são louváveis os eventos que trazem à tona tais questões como o Simpósio Futuros Possíveis, que ocorreu em 2012, em São Paulo.

Enquanto internacionalmente algumas das mais importantes feiras de arte, como a Art Basel e a Arco Madrid, há tempos traçam fóruns específicos, que a cada ano são aprimorados, no Brasil se observa esta estagnação. Entre os motivos desta estagnação encontramos uma série de redirecionamentos, que não podemos ainda mensurar o que ocasionarão à arte em interface com as tecnologias digitais e a ciência.

Estes redirecionamentos começam em 2011, com o encerramento de sólidos projetos do MIS São Paulo em relação à arte e tecnologia, em função de estratégias políticas. Em 2012 outros fomentos específicos foram fechados: o Prêmio Sergio Motta de Arte e tecnologia e os festivais promovidos pela instituição, assim como a Emoção Art.ficial - Bienal Internacional de Arte e Tecnologia do Itaú Cultural e o Rumos na categoria específica para a arte e tecnologia, dois fomentos que incentivavam a produção e ainda contavam com o apoio do ItauLab, um espaço específico de produção, esses via Itaú Cultural. Também a empresa de telefonia Vivo, em 2012, redirecionou sua atuação no campo da arte e tecnologia, o que já constituía uma trajetória promissora e descentralizada pelo país. Se a Vivo mudou de diretoria no Brasil e o Instituto Sergio Motta resolveu repensar a atuação em cultura e mídias digitais, ambos sem explicações condizentes, talvez a explicação mais coerente tenha sido a do Itaú Cultural, que resolve inserir a arte digital no amplo leque da arte contemporânea. 
Se por um lado estas estratégias forçam uma participação mais ativa dos órgãos públicos no campo das artes em interface com o digital, por outro demonstram que um circuito se formou e recebeu incentivos destas instituições, as quais deram as regras à boa parte da produção, demonstrando o jogo de poder eminente também no campo da arte que está mais próxima da cultura digital. Estes redirecionamentos demonstram que a arte digital precisa de suportes legítimos para que possa ser produzida não apenas no âmbito da academia ou dos grupos independentes, mas também com fomentos específicos que possibilitem também sua inserção no mercado e nos acervos, ao menos, de museus de arte contemporânea. Ou quem sabe de instituições específicas que carreguem o espírito deste tempo aliando produção-distribuição-consumo-preservação. Novas produções precisam de espaços adequados para elas, como aconteceu com os museus de arte moderna nos anos 1940-50 e os museus de arte contemporânea nos anos 1970-80.

Gilbertto Prado faz uma importante reflexão sobre a preservação no Brasil em relação a outros países:

[...] o Brasil é mestre em pular etapas, enquanto lá fora existem, ao menos desde os anos 1970, muitos trabalhos de artistas que atuam na linha arte e tecnologia, ou arte digital, como você chama, em coleções públicas, em acervos, museus, coleções particulares que vão ajudar a construir uma certa história de um período, aqui no Brasil é raríssimo, apesar das inúmeras mostras, editais e exposições [...] (PRADO In: GASPARETTO, 2014, p. 116)

Talvez a verdadeira inserção da arte digital no sistema da arte contemporânea aconteça quando pudermos relacionar estas produções digitais e "analógicas" por meio dos acervos das instituições. Para isso é preciso que as discussões sobre as especificidades da produção continuem acontecendo, como é imprescindível o incentivo à produção, só assim poderemos promover encontros coerentes e que ajudem a repensar o sistema vigente. Neste sentido, o pensamento de Guilherme Kujawski (In: GASPARETTO, 2014) é adequado, ao entender que é preciso manter laboratórios específicos, redes de contatos e a teoria específica desta arte, para que as aproximações, que são muito bem-vindas, sejam coerentes.

\section{Conclusão}

Quando perguntados sobre qual seria o lugar da arte digital hoje no Brasil, com o encerramento de fomentos específicos e muito importantes para a manutenção da produção e exposição da arte digital, grande parte dos entrevistados (In: GASPARETTO, 2014) respondem que o lugar desta produção é no sistema da arte contemporânea. Alguns, mesmo que de modos distintos, entendem que o lugar da arte digital atualmente é aquele em paralelo ao sistema da arte contemporânea, seja nos festivais, seja em centros de formação em arte digital. E Daniela Bousso é mais cética ao responder: "nenhum". No entanto, a maior parte dos entrevistados percebe que este diálogo com o sistema da arte contemporânea ainda não aconteceu de fato, ou pelo menos não foi durador. Como eles apontam, os atuais espaços expositivos não dão conta de atender às demandas da produção, os tradicionais agentes da arte contem- 
porânea ainda não dominam o repertório e a teoria da arte digital, sendo o seu lugar ainda instável no tradicional sistema da arte.

Podemos arriscar responder a esta pergunta, dizendo que o lugar da arte digital no Brasil hoje, mesmo sem estes fomentos, é em um sistema particular, que ainda não se deu conta do seu potencial, um sistema que parece desenvolver-se independentemente do mercado ou do mainstream, e de modo genuíno. Este sistema que se desenha para a arte digital e que apresenta fortes antecedentes históricos é composto por agentes que têm formação híbrida; se pensarmos nos novos curadores da arte digital, eles têm formação ou especialização ou ainda foco em artes, mas também em teoria da arteciência-tecnologia e cultura digital. Eles não precisam ser necessariamente da área das artes, podem ser egressos da comunicação, como é o caso de Priscila Arantes, Marília Pasculli ou dos idealizadores do FAD, Tadeus Mucelli Tee e Henrique Roscoe, ou do Salão Xumucuís de Arte Digital, Ramiro Quaresma, entre outros, mas todos estão interessados em artes e em promover a aproximação desta produção com um público mais amplo.

Quanto aos espaços de produção-exposição da arte digital, acreditamos, na esteira do pensamento de Yara Guasque e Maria Luiza Fragoso, que, em alternativa à falta de espaços adequados, esta produção-exposição é articulada nos espaços comunitários, nas redes que se formam para discutir questões de programação e arte, e nos espaços públicos, nas cidades e em meio à natureza, ou ainda em alguns espaços de certo modo institucionalizados, como a Galeria de Arte Digital do SESI-FIESP, ou nos festivais, que são constantemente repensados, como já vem acontecendo.

Ao mesmo tempo a produção em arte-ciência-tecnologia também precisa de obras que trabalham com as tecnologias de ponta, com o desenvolvimento científico. Isto faz parte da pesquisa sobre as potencialidades dos meios técnicos/tecnológicos e é um dos pressupostos da cultura digital. Nada mais natural do que ter artistas inseridos nas pesquisas em alta tecnologia, design de interfaces e desenvolvimento tecnológico. As pesquisas com neurociência, por exemplo, sugerem outras relações e percepções sobre a arte. Então há um campo ainda muito rico para se descobrir e os artistas brasileiros também devem estar imersos nele. Para que isso ocorra é imprescindível financiamento e também a inserção destes artistas em laboratórios e centros de pesquisa que fogem da área de artes, aqui as parcerias se fazem pertinentes.

Podemos pensar, em termos de diálogos, que a própria curadoria vai definindo o que poderá entrar posteriormente para o sistema da arte contemporânea ou para o mercado mais instituído. Isto é algo que já se percebe internacionalmente; se observarmos as Bienais de Veneza e Documentas ou as feiras de arte, perceberemos que muitas das obras e artistas digitais ali expostos já foram legitimados no mundo da New Media Art, ganharam um Prêmio no Ars Electronica, no Vida, da Telefônica, no ARCO BEEP, ou ainda fazem parte do acervo do ZKM ou de outros centros de arte e mídia ao redor do mundo. Esta estrutura que se coloca de um sistema específico fortalece a produção e como menciona Shanken (In: GASPARETTO, 2014), tal sistema é acusado de gueto e, no entanto, é um gueto muito luxuoso internacionalmente.

Este sistema da arte digital é, no entanto, extremamente importante no sentido de não a guetificar, mas de abrigar as discussões e produções, suas especificidades técnicas, tecnológicas e conceituais, a fim de amadurecer as estruturas de produ- 
ção-distribuição-consumo-preservação. Não é à toa que feiras de arte digital, como por exemplo a Unpainted, têm sido criadas, que galerias têm se especializado e que instituições conscientes têm preservado e discutido modos de mantê-la.

Evidentemente, ainda não temos como afirmar se existe realmente um sistema específico para a arte digital no Brasil, ou se o sistema da arte contemporânea vai absorver esta produção e inseri-la em breve no mercado, ou se haverá uma solução híbrida, em diálogo com a cultura digital. Isso porque estamos imersos nesta problemática e ainda não temos o distanciamento necessário para compreendê-la de modo mais claro. Embora acreditemos que a tendência seja uma mistura, cada vez maior, sobretudo quando os estudantes que tomarem contato com a arte digital começarem a assumir papéis de destaque no sistema da arte contemporânea. Curadores como Priscila Arantes, Gisela Domsckhe e Marcello Dantas, entre outros, já provam que esta mistura é possível.

Enfim, acreditamos que a arte digital não deve apenas ser incorporada ao sistema da arte contemporânea seguindo os modelos vigentes neste sistema, mas, como sugere Shanken (In: GASPARETTO, 2014), esta produção deve questionar o status quo do sistema vigente, propondo atualizações. A produção em arte digital deve oferecer novos modelos e estruturas para o sistema da arte contemporânea, mas, antes disso, precisa encontrar e repensar o seu próprio lugar para fortalecer suas estruturas produtivas, expositivas, de consumo e preservação. 


\section{Referências}

ARANTES, P. Arte e mídia: perspectivas da estética digital. São Paulo: Editora Senac, 2005.

BONNE, S. O efêmero tecnológico e a ausência da arte computacional nos acervos brasileiros. Tese de Doutorado UFRGS, 2013.

BOUSSO, V.D. Produção, difusão e mercado nas novas mídias. São Paulo: Instituto Sergio Motta, 2002.

FOSSATTI, M.; GEMETTO, J. Arte joven y cultura digital, 2011. [Livro eletrônico]. Disponível em: < http://www.articaonline.com/descarga-el-e-book-arte-joven-y-cultura-digital >. Acesso em: 24 jul. 2014.

GASPARETTO, D A. O "curto-circuito" da arte digital no Brasil. 1.ed. Santa Maria: Edição da autora, 2014.

GASPARETTO, D. A (Org.). Arte-ciência-tecnologia: o sistema da arte em perspectiva. [Livro eletrônico] 1ed. Santa Maria: Editora Lab Piloto, 2014. Disponível em: < http:// artedigitalbr.wix.com/circuito >. Acesso em: 24 jul. 2014.

KERN, D. Tradição em Paralaxe: a novíssima arte contemporânea sul-brasileira e as "velhas-tecnologias". Porto Alegre: Edições Museu Julio de Catilhos, 2013.

JENKINS, H. Cultura da convergência. Trad. Susana Alexandria. - 2 ed. - São Paulo: Aleph, 2009.

MACHADO, A. Tecnologia e arte contemporânea: como politizar o debate. Revista de Estudios Sociales nำ 22, diciembre de 2005, 71-79.

PRADO, G. Arte telemática: dos intercâmbios pontuais aos ambientes virtuais multiusuário/Apresentação Arlindo Machado, Julio Plaza - São Paulo: Itaú Cultural, 2003.

QUARANTA, D. Media, New Media, Postmedia. Milão: Postmedia Srl, 2010.

SAVAZONI, R; COHN, S. Cultura digital.br. Rio de Janeiro: Beco do Azougue, 2009.

SHANKEN, E. Contemporary Art and New Media:Toward a Hibrid Discourse? Disponível em: < http://hybridge.files.wordpress.com/2011/02/hybrid-discourses-overview-4.pdf >. Acesso em 28/07/2014.

SOGABE, M. Arte-tecnologia no Brasil: tecnologias e gerações. In: III Simpósio Nacional ABCiber - ESPM/SP, 2009. 
Débora Aita Gasparetto

Doutoranda em Artes Visuais da Universidade Federal do Rio Grande do Sul - UFRGS Santa Maria, Rio Grande do Sul, Brasil deboraaitagasparetto@gmail.com 